\title{
Detection of ULF geomagnetic signals associated with seismic events in Central Mexico using Discrete Wavelet Transform
}

\author{
O. Chavez ${ }^{1}$, J. R. Millan-Almaraz ${ }^{1}$, R. Pérez-Enríquez ${ }^{2}$, J. A. Arzate-Flores ${ }^{2}$, A. Kotsarenko ${ }^{2}$, J. A. Cruz-Abeyro ${ }^{2}$, \\ and E. Rojas ${ }^{1}$ \\ ${ }^{1}$ División de Investigación y Posgrado, Facultad de Ingeniería, Universidad Autónoma de Querétaro, Centro Universitario, \\ Cerro de las Campanas s/n, Querétaro, Querétaro, C.P. 76010, México \\ ${ }^{2}$ Centro de Geociencias (CGEO), Juriquilla, UNAM, Apdo Postal 1-742, Centro Querétaro, Querétaro, México, \\ C.P. 76001 , México
}

Received: 14 April 2010 - Revised: 12 July 2010 - Accepted: 5 November 2010 - Published: 14 December 2010

\begin{abstract}
The geomagnetic observatory of Juriquilla Mexico, located at longitude $-100.45^{\circ}$ and latitude $20.70^{\circ}$, and $1946 \mathrm{~m}$ a.s.l., has been operational since June 2004 compiling geomagnetic field measurements with a three component fluxgate magnetometer. In this paper, the results of the analysis of these measurements in relation to important seismic activity in the period of 2007 to 2009 are presented. For this purpose, we used superposed epochs of Discrete Wavelet Transform of filtered signals for the three components of the geomagnetic field during relative seismic calm, and it was compared with seismic events of magnitudes greater than $M_{\mathrm{S}}>5.5$, which have occurred in Mexico. The analysed epochs consisted of $18 \mathrm{~h}$ of observations for a dataset corresponding to 18 different earthquakes (EQs). The time series were processed for a period of $9 \mathrm{~h}$ prior to and $9 \mathrm{~h}$ after each seismic event. This data processing was compared with the same number of observations during a seismic calm. The proposed methodology proved to be an efficient tool to detect signals associated with seismic activity, especially when the seismic events occur in a distance $(D)$ from the observatory to the $\mathrm{EQ}$, such that the ratio $D / \rho<1.8$ where $\rho$ is the earthquake radius preparation zone. The methodology presented herein shows important anomalies in the Ultra Low Frequency Range (ULF; $0.005-1 \mathrm{~Hz}$ ), primarily for 0.25 to $0.5 \mathrm{~Hz}$. Furthermore, the time variance $\left(\sigma^{2}\right)$ increases prior to, during and after the seismic event in relation to the coefficient D1 obtained, principally in the $\mathrm{Bx}(\mathrm{N}-\mathrm{S})$ and By (E-W) geomagnetic components. Therefore, this paper proposes and develops a new methodology to extract the abnormal signals of the geomagnetic anomalies related to different stages of the EQs.
\end{abstract}

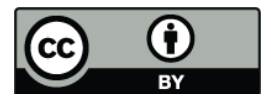

Correspondence to: $\mathrm{O}$. Chavez (omar.chavez@uaq.mx)

\section{Introduction}

Different reports of electro-magnetic (EM) anomalies associated with earthquakes encompass a large frequency range, ranging from quasi-dc to Megahertz. These anomalies are associated with EQs which typically occur during, but sometimes prior to, seismic activity. Such anomalies have been reported for several decades (Parrot and Johnston, 1989; Johnston, 1997; Kushwah, 2009). For example, at the low end of the frequency range, Johnston and Mueller (1987) noticed magnetic field offsets coinciding with the 1986 North Palm Springs earthquake, which occurred in Southern California close to the San Andreas Fault. Johnston et al. (1994) also observed magnetic offsets of the rupture mechanism during the 1992 Landers earthquake in the same region. At the high frequency end, radio emissions of $18 \mathrm{MHz}$ were recorded on multiple Northern Hemisphere receivers for approximately $15 \mathrm{~min}$ before the great Chilean earthquake in 1960 (Warwick et al., 1982).

Geomagnetic phenomena, especially in the ULF range have attracted scientific interest resulting in more articles being published on this topic (Smirnova et al., 2004; Serita et al., 2005; Kushwah et al., 2009). The EM anomalous signals in the ULF range have been observed before a series of destructive earthquakes in different highly populated regions around the globe. Fraser-Smith et al. (1990) recorded anomalous magnetic field fluctuations prior to the earthquake in Loma Prieta in central California on 17 October $1989\left(M_{\mathrm{S}}=7.1\right)$. In particular, they claim that there was an amplitude increase of geomagnetic activity for approximately two weeks prior to the main shock. This perturbation continued until an even larger-amplitude increase that began three hours before the main shock. Other anomalous EM signals in the ULF range possibly related to earthquakes were recorded several hours prior

Published by Copernicus Publications on behalf of the European Geosciences Union. 
to the EQ in Spitak, Armenia $\left(M_{\mathrm{S}}=6.9\right)$, on 7 December 1988 (Molchanov et al., 1992; Kopytenko et al., 1993). Furthermore, anomalous emissions related to the Guam $\mathrm{EQ}$, were observed two weeks prior and then again a few days before the main event on 8 August $1993\left(M_{\mathrm{S}}=8.0\right)$ (Hayakawa et al., 1996). Recent studies in the ULF range reveal a possible connection between the impact of the earthquake preparation process and ionospheric resonance phenomena prior to crustal rupture (Grimalsky et al., 2010).

The primary advantage of ULF electromagnetic emission is that it can circulate just below the crust of the Earth's surface without any significant attenuation if they are generated at typical earthquake nucleation depths of approximately $10 \mathrm{~km}$ (Serita et al., 2005). EM ULF signals were shown to be in the range of $0.005-1 \mathrm{~Hz}$ (Kopytenko et al., 1993) and can be observed as a combination of several physical phenomena, namely: (1) geomagnetic activity of the magnetosphere, for example geomagnetic storms caused by the solar activity; (2) man-made noise; and (3) and other effects such as seismo-magnetic emissions (Serita et al., 2005; Hayakawa et al., 2008; Ida et al., 2008). Therefore, a key issue of a study of ULF anomalies is to discriminate signals related to EQs from signals of other origin. Different methods have been proposed to solve this problem, such as the polarization analysis of EM waves (Kawate et al., 1998; Kotsarenko et al., 2004, 2005; Hayakawa et al., 2008); fractal and multi-fractal analysis (Hayakawa et al., 1999; Gotoh et al., 2003; Smirnova et al., 2004; Kotsarenko et al., 2004, 2005, 2007); the Principal Component Analysis (PCA) (Hattori et al., 2004; Kotsarenko et al., 2005); location of the area of seismogenic geomagnetic disturbances (Ismaguilov et al., 2001; Kopytenko et al., 2001); and signal/noise discrimination by using the transfer functions (Harada et al., 2004), among others. All the abovementioned methods are applied to improve the detection of the ULF signals associated with seismogenic phenomena at different frequencies (Hayakawa et al., 2008), and to the understanding of electromagnetic phenomena associated with tectonic and volcanic activity.

In this paper, ULF signals applying the Discrete Wavelet Transform (DWT) method are analysed, which has proven to be an efficient tool for transient signal analysis to assess time shifting frequencies related to magnetic field offsets associated with rupture mechanisms in a wide range of applications (Alperovich and Zheludev, 1997; MillanAlmaraz et al., 2008). The EQ signals are superposed pulses or bursts within certain carrier frequencies regarded as the background field, which theoretically can be extracted on the basis of the DWT approach, known to be effective for this purpose. The DWT methodology can provide relevant information related to the time position and time offsets; between the perturbed ULF signals using and the background field through finite impulse response (FIR) filtering. The work of Alperovich and Zheludev (1997) takes advantage of this methodology using the wavelet types of symmlets (8th order) and splines (4th order) to determine anomalous geomagnetic activity two days before the occurrence of the Loma Prieta EQ $\left(M_{\mathrm{s}}=7.1\right)$ (San Francisco, 18 October 1989), the distance to the testing stations was approximately 300 to $1000 \mathrm{~km}$. The authors detected an increase in geomagnetic activity as little as $5 \mathrm{~h}$ prior to the main seismic shock. However, this and other works (Johnston et al., 1997; Kawate et al., 1998; Kushwah et al., 2009) focused on a single seismic event, which limits the scope of their findings.

In this research, 18 seismic events were analysed by estimating the D1 coefficient with the DWT method. The variance is utilized in order to measure the fluctuations of D1 geomagnetic signals. Also, a comparison between the epochs of seismic and magnetic field activity with respect to seismic calm periods is presented herein. The background magnetic field observations correspond within the earthquake radius preparation zone $(\rho)$, as has been stated by Dobrovolsky et al. (1979) where $\rho=10^{0.43 M_{\mathrm{s}}} \mathrm{km}$ when $M_{\mathrm{S}}$ is the given magnitude of the earthquake. The data analysis corresponded to geomagnetic time series and EQ events of magnitude $M_{\mathrm{S}}>5.5$ that occurred during the period from 2007 to 2009 . The characteristics of the seismic events are presented in the Table 1. This table is organized according to the $D / \rho$ ratio where $D$ is the distance between the seismic event and the Juriquilla observatory, where the data was recorded and analysed.

\section{Dataset}

The analysed geomagnetic data was recorded at the Juriquilla station, localized in Central Mexico, with geographic coordinates longitude $-100.45^{\circ}$ and latitude $20.70^{\circ}$, and $1946 \mathrm{~m}$ a.s.l. The fluxgate magnetometer measured the 3 mutually orthogonal components of the magnetic field $\mathrm{Bx}$, $\mathrm{By}$, and Bz. The first two correspond to the two horizontal (N-S and E-W) components, while the later corresponds to the vertical component. The sampling rate frequency of the instrument is $1 \mathrm{~Hz}$, with a GPS system used for data synchronization. The acquired time series of the three components of the magnetic field, which were considered for the 18 events, comprise $9 \mathrm{~h}$ before the occurrence of the main seismic event up to $9 \mathrm{~h}$ after it. For comparison purposes, random analyses during periods of seismic calm were used. In order to discriminate the geomagnetic activity of the magnetosphere due to the solar activity and cultural noise all the data series were compared to the Dst index as found on the Kyoto observatory webpage. The Hourly Equatorial values are in between -21 and $8 \mathrm{nT}$ during the analysed period; see Table 2 (http://wdc.kugi.kyoto-u.ac.jp/dstdir/).

\section{Discrete Wavelet Transform method (DWT)}

The DWT is an alternative signal processing method for transient state analysis and new perspectives and advantages must be better quantified, this yields relevant 
Table 1. Earthquakes occurred in Mexico during 2007-2009 selected for this analysis. Year/month/day/hour/min are: the exact time of the EQ (Local Time); Latitude and Longitude: the geographic coordinates of the epicentre, magnitudes and depth: magnitude and depth of the EQ, Distance: the distance between the epicentre and Juriquilla station, $\rho$ : is the radius of the EQ preparation zone estimated by Dobrovolsky equation. The EQ magnitudes are presented in bold.

\begin{tabular}{lcccccccccccc}
\hline Event & Year & Month & Day & Hour & Min & Longitude & Latitude & $\begin{array}{c}\text { Magnitude, } \\
\boldsymbol{M}_{\mathbf{s}}\end{array}$ & $\begin{array}{c}\text { Depth, } \\
\mathrm{km}\end{array}$ & $\begin{array}{c}\text { Distance, } \\
\mathrm{km}\end{array}$ & $\begin{array}{c}\rho, \\
\mathrm{km}\end{array}$ & Distance/ $\rho$ \\
\hline 1 & 2007 & 4 & 13 & 00 & 42 & -100.44 & 17.09 & $\mathbf{6 . 3}$ & 41 & 401 & 512 & 0.78 \\
2 & 2007 & 11 & 26 & 11 & 41 & -93.36 & 15.28 & $\mathbf{5 . 6}$ & 9 & 259 & 256 & 1.01 \\
3 & 2008 & 9 & 23 & 21 & 33 & -105.16 & 17.16 & $\mathbf{6 . 4}$ & 42 & 634 & 565 & 1.12 \\
4 & 2008 & 4 & 27 & 19 & 06 & -100.01 & 18.05 & $\mathbf{5 . 6}$ & 52 & 296 & 256 & 1.16 \\
5 & 2009 & 5 & 22 & 14 & 24 & -98.44 & 18.13 & $\mathbf{5 . 7}$ & 45 & 360 & 282 & 1.28 \\
6 & 2007 & 11 & 6 & 00 & 35 & -100.14 & 17.08 & $\mathbf{5 . 6}$ & 9 & 403 & 256 & 1.57 \\
7 & 2008 & 10 & 16 & 14 & 41 & -92.5 & 13.87 & $\mathbf{6 . 6}$ & 23 & 1132 & 689 & 1.64 \\
8 & 2008 & 2 & 12 & 06 & 50 & -94.54 & 16.19 & $\mathbf{6 . 6}$ & 90 & 1142 & 689 & 1.66 \\
9 & 2007 & 7 & 5 & 20 & 09 & -94.1 & 16.9 & $\mathbf{6 . 2}$ & 100 & 790 & 463 & 1.71 \\
10 & 2007 & 6 & 13 & 14 & 29 & -91.43 & 13.26 & $\mathbf{6 . 6}$ & 20 & 1267 & 689 & 1.84 \\
11 & 2007 & 9 & 1 & 14 & 14 & -109.53 & 24.33 & $\mathbf{6 . 3}$ & 20 & 1014 & 511 & 1.98 \\
12 & 2009 & 5 & 3 & 11 & 21 & -91.89 & 14.53 & $\mathbf{5 . 9}$ & 77 & 1136 & 344 & 3.30 \\
13 & 2007 & 3 & 12 & 20 & 58 & -110.92 & 26.46 & $\mathbf{5 . 8}$ & 16 & 1245 & 311 & 4.00 \\
14 & 2008 & 1 & 4 & 19 & 56 & -92.12 & 13.83 & $\mathbf{5 . 6}$ & 63 & 1033 & 255 & 4.05 \\
15 & 2008 & 3 & 13 & 17 & 01 & -93.87 & 14.17 & $\mathbf{5 . 5}$ & 16 & 1004 & 231 & 4.35 \\
16 & 2007 & 3 & 28 & 08 & 28 & -109.61 & 25.43 & $\mathbf{5 . 5}$ & 10 & 1084 & 231 & 4.69 \\
17 & 2009 & 6 & 3 & 16 & 37 & -109.22 & 19.72 & $\mathbf{5 . 6}$ & 7 & 1298 & 255 & 5.09 \\
18 & 2008 & 2 & 9 & 01 & 12 & -115.12 & 32.34 & $\mathbf{5 . 5}$ & 10 & 1943 & 231 & 8.41 \\
\hline
\end{tabular}

Table 2. Dst Index obtained from Kyoto observatory web page corresponding with the 9 principal events analysed.

\begin{tabular}{lrrrrrrrrrrrrrrrrrr}
\hline $\begin{array}{l}\text { Event } \\
\text { Number }\end{array}$ \\
\hline 1 & -14 & -12 & -8 & -8 & -9 & -9 & -8 & -8 & -12 & -13 & -12 & -11 & -12 & -14 & -17 & -15 & -14 & -13 \\
2 & -15 & -15 & -14 & -16 & -20 & -21 & -18 & -16 & -17 & -17 & -15 & -11 & -11 & -9 & -10 & -11 & -13 & -16 \\
3 & 0 & 0 & -1 & -2 & -2 & -2 & -1 & -2 & -5 & -4 & -2 & -2 & 2 & 4 & 3 & 2 & -1 & -3 \\
4 & -14 & -11 & -10 & -9 & -8 & -7 & -8 & -10 & -7 & -3 & -2 & -3 & -3 & -2 & 1 & 3 & 6 & 8 \\
5 & 6 & 6 & 5 & 1 & -5 & -6 & -10 & -7 & -8 & -9 & -9 & -7 & -8 & -3 & -4 & -4 & 1 & 2 \\
6 & -2 & -2 & -2 & 0 & 1 & 1 & 2 & 2 & 3 & 3 & 4 & 5 & 6 & 7 & 7 & 7 & 6 & 5 \\
7 & -20 & -19 & -19 & -19 & -18 & -19 & -18 & -19 & -21 & -19 & -16 & -13 & -11 & -12 & -13 & -11 & -11 & -11 \\
8 & -14 & -16 & -16 & -18 & -18 & -17 & -17 & -17 & -13 & -12 & -4 & -3 & -6 & -5 & -10 & -19 & -20 & -15 \\
9 & -11 & -9 & -10 & -11 & -11 & -10 & -8 & -7 & -10 & -8 & -8 & -7 & -4 & -5 & -4 & -1 & -1 & -4 \\
\hline
\end{tabular}

tools to search for localized perturbations shadowed by the noise background (Alperovich and Zheludev, 1997). The capability of the DWT to examine the time-frequency evolution of a signal makes it a useful tool for the analysis of noisy signals with time shifting frequencies (Millan-Almaraz et al., 2008).

\subsubsection{Definition and implementation}

The Continuous Wavelet Transform (CWT) consists of the convolution between a signal $x(t)$ and a mother wavelet function $\psi(t)$ defined by Eq. (1) (Kaiser, 1994). The CWT
Table 3. DWT decomposition bandwidths in $\mathrm{Hz}$ for a sampling frequency $f_{\mathrm{s}}=1 \mathrm{~Hz}$.

\begin{tabular}{lll}
\hline Level & Approximation (An) & Detail (Dn) \\
\hline 1 & A1: $0-0.25 \mathrm{~Hz}$ & D1: $0.25-0.5 \mathrm{~Hz}$ \\
2 & A2: $0-0.125 \mathrm{~Hz}$ & D2: $0.125-0.25 \mathrm{~Hz}$ \\
3 & A3: $0-0.0625 \mathrm{~Hz}$ & D3: $0.0625-0.125 \mathrm{~Hz}$ \\
\hline
\end{tabular}


involves a time scale decomposition of $x(t)$, related to the frequency where $\tau$ represents a time shifting of the wavelet basis function $\psi(t)$ across $x(t)$. The second part of the CWT involves $s$ and it is defined as $\mid 1 /$ frequency $\mid$ and corresponds to frequency information. Scaling either expands or compresses a signal (Mallat, 1999).

$X_{\mathrm{WT}}(\tau, s)=\frac{1}{\sqrt{|s|}} \int x(t) \cdot \psi^{*}\left(\frac{t-\tau}{s}\right) d t$

The DWT is the discrete time version of the CWT as described by Eq. (2), where $n$ represents the discrete time index, $x(n)$ is the discrete time original signal, $h(n)$ is the discrete time wavelet basis function, $N$ is the total number of $x(n)$ samples, $j$ is the time scaling, and $k$ is the shifting of the discrete wavelet function $h(n)$ through the input signal $x(n)$.

$\mathrm{WC}_{j, k}=\sum_{N} x(n) \overline{h_{j, k}(n)}$

The DWT implementation is based on Mallat algorithm using a bank of FIR filters connected in cascade for signal separation by definition levels (Mallat, 1999). Based on the Nyquist theorem, the sampling frequency $f_{\mathrm{s}}$ must be at least twice as large as the highest frequency $f_{\mathrm{c}}$ contained in the signal as stated in Eq. (3).

$f_{\mathrm{s}} \geq 2 f_{\mathrm{c}}$

The original signal $x(n)$ is separated into its high and low frequency components by applying a low pass filter (LPF) and a high pass filter (HPF) in parallel, with bandwidths of [0 to $\left.f_{\mathrm{c}} / 2\right]$ and $\left[f_{\mathrm{c}} / 2\right.$ to $f_{\mathrm{c}}$ ], respectively. Each filtering stage reduces the number of samples by half to obtain the approximation coefficients A1 corresponding to LPF [0 to $\left.f_{\mathrm{c}} / 2\right]$ and detail coefficients D1 for the HPF [ $f_{\mathrm{c}} / 2$ to $f_{\mathrm{c}}$ ]. A new filtering stage is applied to the previously obtained A1 approximation coefficients in order to separate its subsequent low and high frequency components generating new coefficients, A2 for the frequency range [0 to $f_{\mathrm{c}} / 4$ ] from the LPF and D2 for $\left[f_{\mathrm{c}} / 4\right.$ to $\left.f_{\mathrm{c}} / 2\right] \mathrm{HPF}$, in the Table 3 the DWT decomposition bandwidths in $\mathrm{Hz}$ for a sampling frequency $f_{\mathrm{s}}=1 \mathrm{~Hz}$ is observed. This process is repeated in a recursive way to gather the remaining detail coefficients. The DWT decomposition in bandwidths is made for a sampling frequency of $f_{\mathrm{s}}=1 \mathrm{~Hz}$ as is the case for the sampling frequency of the magnetometer used.

In Fig. 1, a synthetically generated ULF transient signal with a sampling frequency of $1 \mathrm{~Hz}$ is shown, in which three sinusoidal wave frequency components $f_{1}, f_{2}$, and $f_{3}$ are considered. These components show a frequency and an amplitude of $0.01 \mathrm{~Hz}$ and 0.6 for $f_{1}, 0.2 \mathrm{~Hz}$ and 0.1 for $f_{2}$ and $0.4 \mathrm{~Hz}$ and 0.4 for $f_{3}$. Note that $f_{1}$ and $f_{2}$ are present all the time but $f_{3}$ is present only for the duration between 20 and $40 \mathrm{~s}$ and it appears again in the period of time between 80 and $90 \mathrm{~s}$. This implies that the time position of the
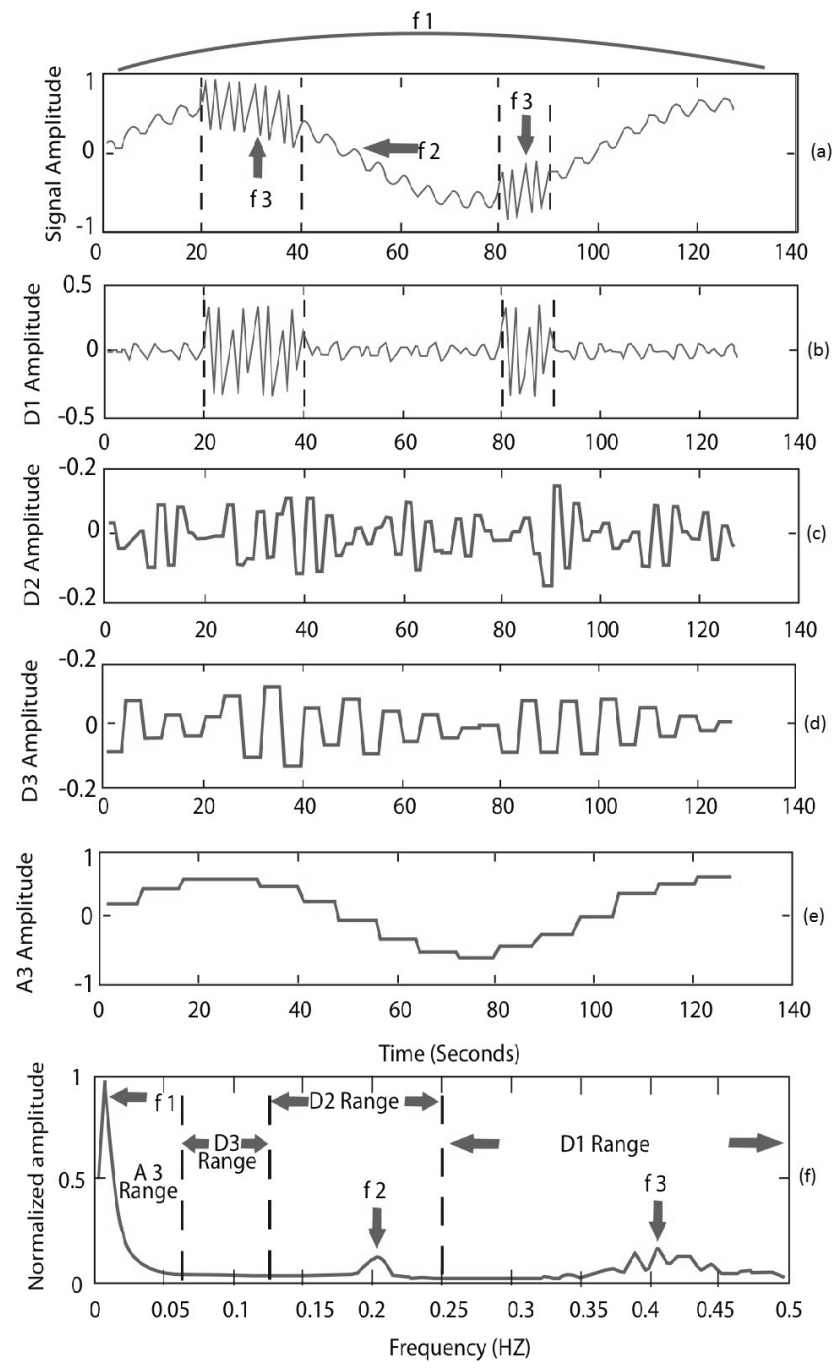

Fig. 1. Comparison between FFT Power spectrum and DWT timefrequency decomposition analysis, for a synthetically generated ULF transient signal.

disturbance only can be observed by applying the DWT and, also can be seen its correspondent amplitude for each level.

Applying the FFT to $x(n)$ the power spectrum is obtained as illustrated in Fig. 1f where the presence of the components $f_{1}, f_{2}$ and $f_{3}$ in frequency domain and its amplitude can be seen. However, for this purpose and by using this methodology it is not possible to determine the exact time at which an specific frequency such as $f_{3}$ appears. The disadvantage of the FFT power spectrum is that for noisy signals, as the ones analysed here, several undesired noise frequency peaks appear close to that of primary interest $\left(f_{3}\right)$. In contrast, the DWT decomposition permits, with the signals compiled, separating the original signal $x(n)$ into the different frequency components and permits us determine the time where a specific frequency appears. 


\subsubsection{DWT based geomagnetic wave analysis}

The proposed methodology consists of applying the DWT time-frequency decomposition to geomagnetic signals, in a superposed epoch analysis; periods of seismic calm and periods of seismic activity are analysed. This considers different distances from the epicentre of the EQ to the observatory. Also, several geomagnetic signals during seismic calm periods $\left(M_{\mathrm{S}}<4.5\right)$ were selected and compared using the same procedure to test the background noise level. Several experimental DWT runs were carried out using different wavelet mother functions and many DWT filtered levels on the three components of the earth geomagnetic field. After the experimental runs it was found that Daubechies 1 (DB1) wavelet function generates the best results enhancing correlation with associated seismic events in nine of the $18 \mathrm{EQs}$ analysed. The other 9 events did not show good correlations. Those events correspond with the $D / \rho$ ratio greater than 1.8. As a result, D1 was identified as the best coefficient for gathering seismic information. However, D2, D3 and A3 (see Fig. 2) were also considered for the DWT decomposition of the ULF signals in order to explain the processes associated with seismic events for the different frequency bands, the principal problems observed is that statistically is lesser important in comparison with the D1 variance. The problem is also associated with the frequency data sampling, in future works the principal aim of this investigation is to have a system that can compiles the information above the $1 \mathrm{~Hz}$ frequency.

In Fig. 2, a detailed comparison between FFT spectrum (Fig. 2f) and DWT time-frequency decomposition (Fig. 2ad) is presented, where both the seismic calm signals (left-side plots) and the seismic activity signals (right-side plots) can be observed. Notice the occurrence of one peak prior to (Preseismic event zone) and another after the main shock (Post seismic event zone). In the Fig. 2a the original ULF signals for seismic calm and activity, respectively, are presented, followed by DWT signal decomposition into D1, D2, D3 and A3 filter output signals, where an amplitude increase in the seismic activity signals can be observed. For comparison the FFT spectrum in frequency domain is presented in $(f)$, where no significant differences in D1, D2 or D3 zones can be seen. Only the Bx component analysis is presented here. Components $\mathrm{By}$ and $\mathrm{Bz}$ are discussed later in the text. From this comparison, it can be established that the DWT method with D1 filter level allows the observation of ULF signal perturbations that can be associated with seismic events. According to example of Fig. 2, that corresponds to event 3 (Table 1), magnetic perturbations occur about 2 and $3 \times 10^{4} \mathrm{~s}$ (about $8 \mathrm{~h}$ ) before the main shock and about 1 to $2 \times 10^{4} \mathrm{~s}$ (about $5.5 \mathrm{~h}$ ) after it. These perturbations are remarked by open circles.

To evaluate the significance of the results, a statistical analysis to all DWT (DB1) signals based on variance calculation algorithm defined by Eq. (6) is performed. Here, $\sigma^{2}$ is the time variance at detail level D1, $a$ and $b$ are the lower and upper limits for the region of interest, $y_{\mathrm{DL}}(n)$ is the input sequence at the detail level and $\bar{y}$ is the mean value of $y_{\mathrm{DL}}(n)$

$$
\sigma^{2}=\frac{1}{b-a} \sum_{n=a}^{b}\left\{\left[y_{\mathrm{DL}}(n)-\bar{y}\right]^{2}\right\} \text {. }
$$

\section{Results and discussion}

In Fig. 3, it is shown the superposed wavelet signals (D1) for epochs of 9 seismic events with different geographical locations, for each of the three components of the magnetic field (three columns), and where the main seismic shock is shown with a white arrow. The Fig. 3a (upper three plots) shows preseismic and postseismic perturbations associated with EQs of magnitude $M_{\mathrm{s}}>5.5$ and Dobrovolsky ratio of $D / \rho<1.8$ (encircled spikes). Figure $3 \mathrm{~b}$ shows the obtained results for the $9 \mathrm{EQs}$ of magnitude $M_{\mathrm{S}}>5.5$ but with a larger than 1.8 Dobrovolsky ratio. In Fig. 3c, the DWT (D1) for time series corresponding to seismically calm periods $\left(M_{\mathrm{S}}<4.5\right)$ is presented, where no spikes are observed. The superposed epoch analysis was performed on the basis of $9 \mathrm{~h}$ before and $9 \mathrm{~h}$ after each seismic event in all cases, considering the time 0 , the specific time of the occurrence of the EQ. For the case that the ratio $D / \rho>1.8$ (Fig. 3b) only the $\mathrm{Bz}$ component shows scattered spikes, but there is no apparent relation with the main shock. The third case (Figs. 3c) is used for comparison purposes; in this case the signal processed for all the period range remains undisturbed in the absence of seismic activity.

In Fig. 4, the statistical significance of the DWT transforms for the three components $(\mathrm{a}, \mathrm{b}$ and $\mathrm{c})$ and for the three cases discussed above is presented. The results correspond to running D1 data windows each of 1024 samples. As observed, there are significant variations of $\sigma^{2}$ for the three components, being the first case $\left(M_{\mathrm{S}}>5.5\right.$ and ratio $D / \rho<1.8)$ that provides statistical significant perturbation that could be associated with the occurrence of the EQs. It is observed that the $\sigma^{2}$ increase before, during, and after the seismic event primarily on Bx (a) and By (b), but also on $\mathrm{Bz}$ (c). During the main shock is showed that the $\sigma^{2}$ is close to the mean value of a seismic calm analysis. In this case, $\mathrm{D} 1(0.25-0.5 \mathrm{~Hz}) \sigma^{2}$ value presents the highest difference between seismic calm and seismic activity filtered signals. The Bx geomagnetic component shows maximum variance in three different time ranges with respect to the $\mathrm{EQ}$ shocks: $8.5-4.5 \mathrm{~h}$ before, between $2 \mathrm{~h}$ before and $2 \mathrm{~h}$ after and from 2.5 to $4.5 \mathrm{~h}$ after the main EQs. The By component results are in Fig. 4b, and show also important variance for the first case $\left(M_{\mathrm{S}}>5.5\right.$ and Dobrovolsky ratio of $\left.D / \rho<1.8\right)$, however of lesser differences. For both components, the signal suddenly falls considerably around the main EQs. Finally, the $\mathrm{Bz}$ component results are shown in Fig. 4c, 

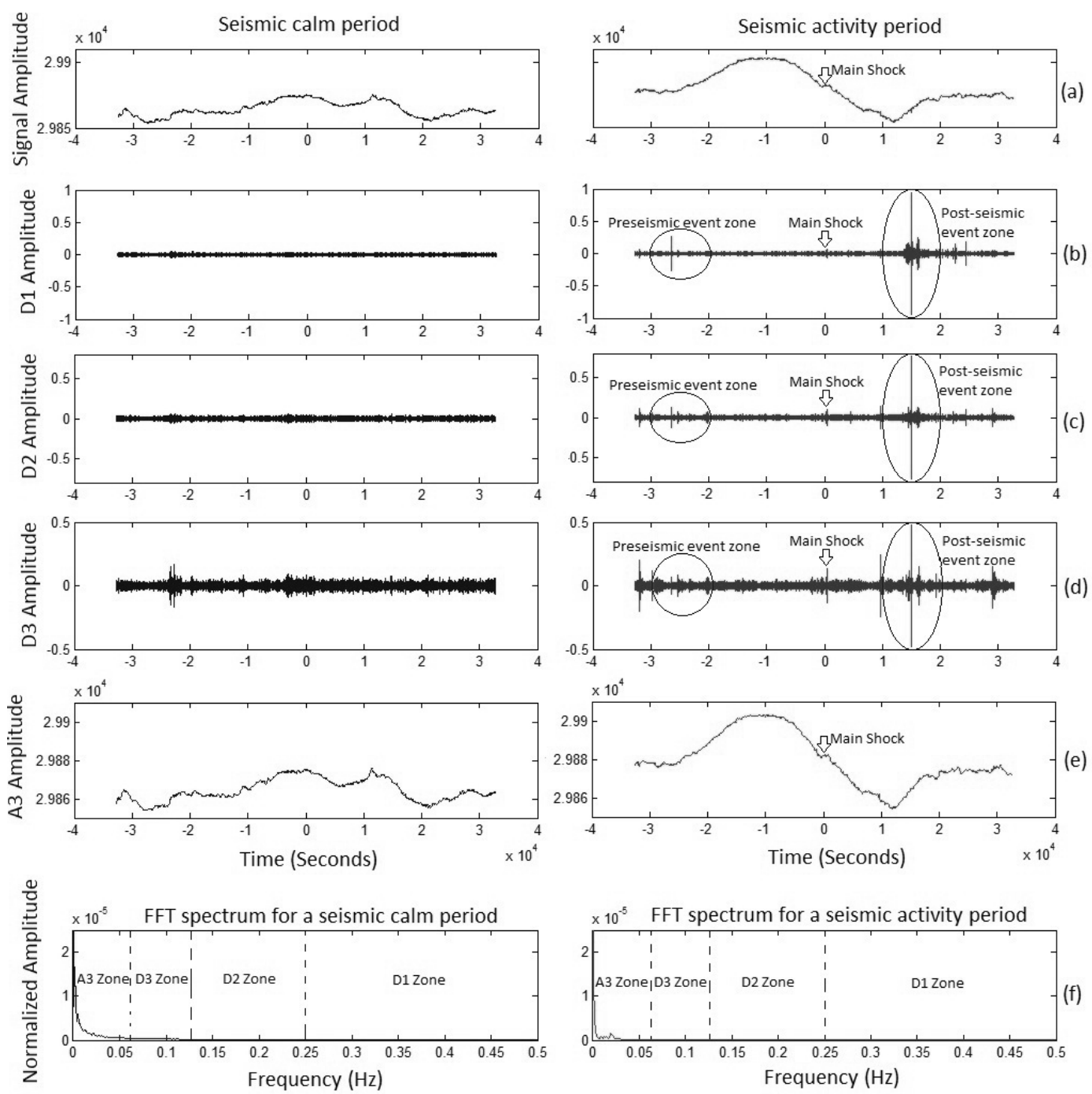

Fig. 2. Comparison between FFT spectrum and DWT time-frequency decomposition analysis; for a seismic calm, and with seismic activity. The main seismic shock is shown with a white arrow.
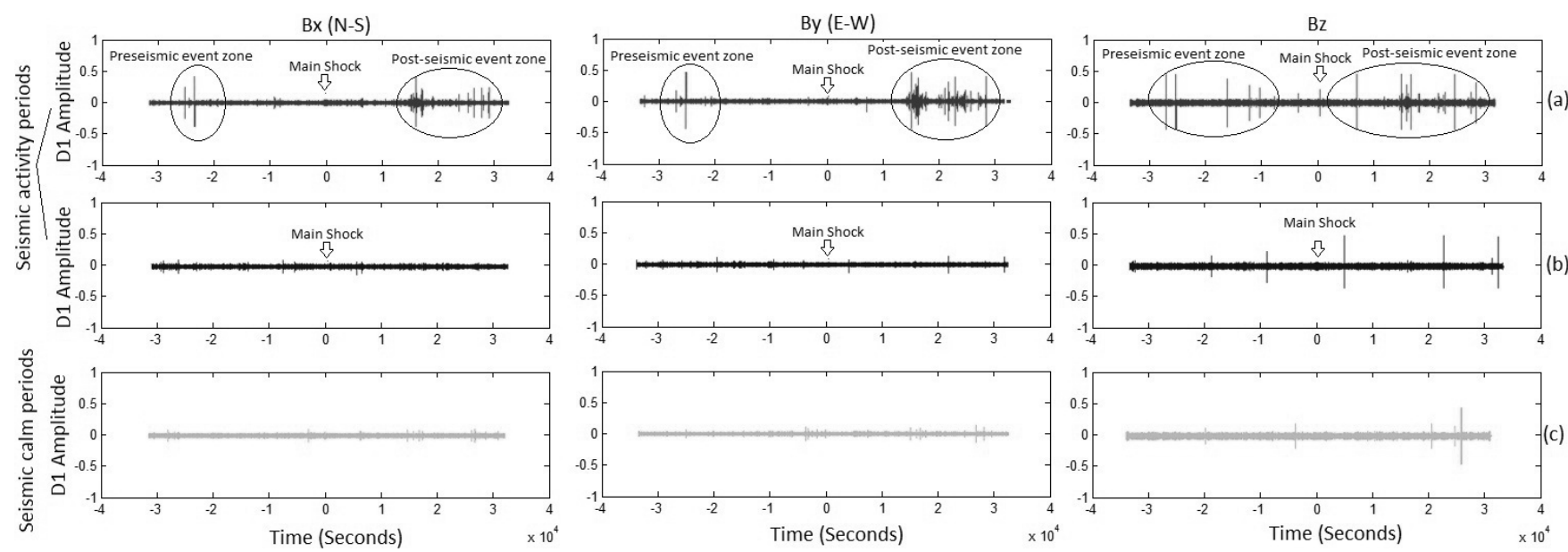

Fig. 3. Wavelet Discrete Transform of the three geomagnetic components in superposed epochs for the three conditions of seismic activity in the ULF frequency range $f=0.25-0.5 \mathrm{~Hz}$. 

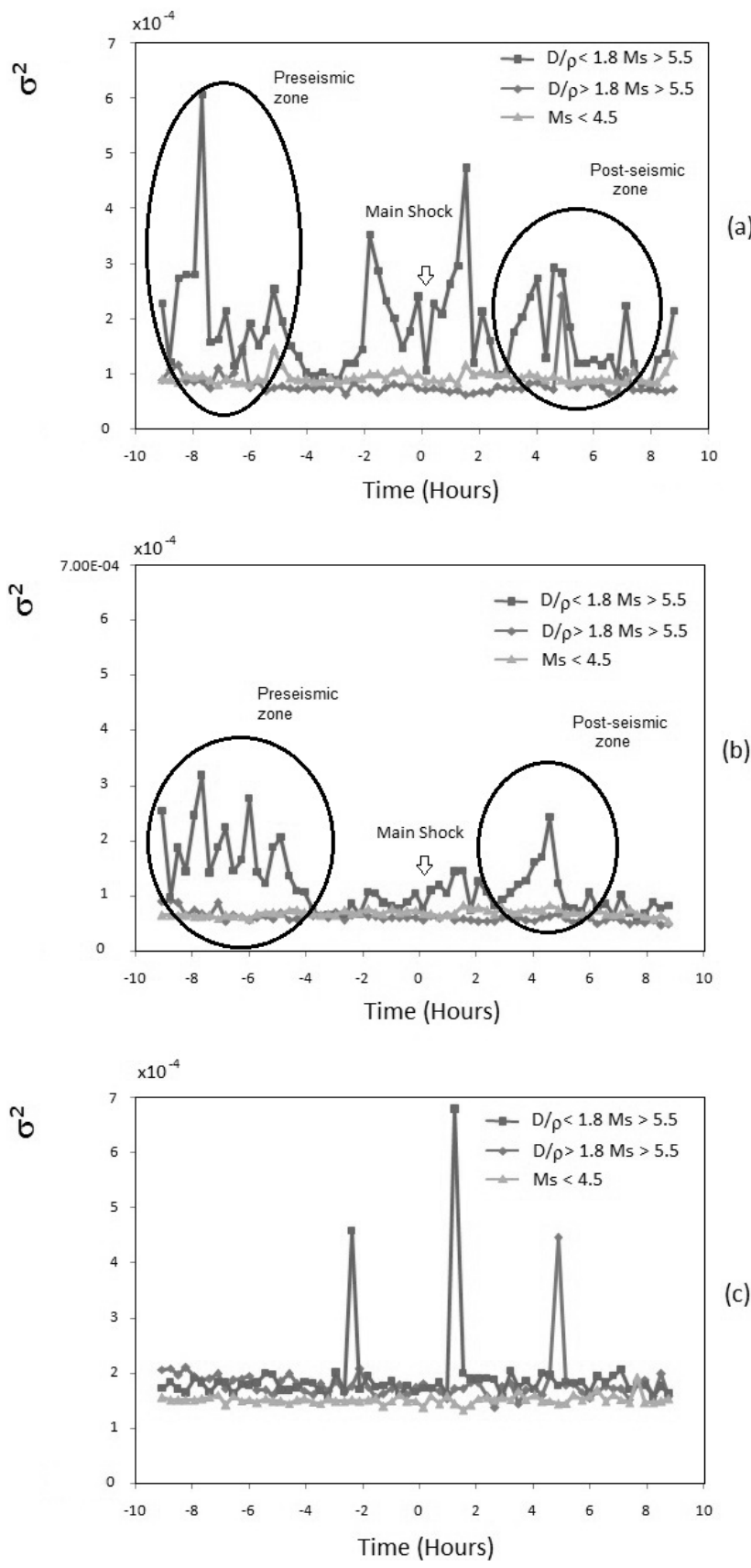

Fig. 4. Variance of the DWT corresponding to the D1 level for the three geomagnetic components; Bx (a), By (b), and Bz (c).

\section{Conclusions}

A methodology that was applied to the geomagnetic data acquired at Juriquilla station is described herein. Three geomagnetic field components behaved in different ways. Signals associated with seismic events data are reported, and the observation time depending on the particular geomagnetic component is analysed. Accordingly, the proposed signal processing methodology consists of applying a detail level 1 DWT filter using a DB1 wavelet mother function to the existing data in order to obtain frequency components. This corresponds to associated seismic anomalies of the geomagnetic signal within the predetermined favourable frequency range, namely, 0.25$0.5 \mathrm{~Hz}$. Furthermore, these investigators have information regarding other bandwidths; however, these possess less statistical basis. In the analysed frequency, variance increases prior to, during and after the seismic event by using the coefficient D1 as is observed primarily in the $\mathrm{Bx}$ and By geomagnetic component. These indicate an important statistical complement of the methodology. Within this range the $\sigma^{2}$ is more informative than the other bandwidths analysed; the differences principally were observed and reveals that the geomagnetic anomalies in the ULF range are within $D / \rho<1.8$. In this case, it also indicates that relevant information can be obtained from a distance of approximately $790 \mathrm{~km}$ from the testing station. Furthermore, anomalies in EM signals appeared within the DWT filtered signals corresponding to events having the characteristics of $D / \rho<1.8$ and $M_{\mathrm{s}}>5.5$. Such signals can be associated with the seismic processes as has been reported by other investigators. They typically occur during, but sometimes prior to seismic activity, and after the preparatory phase of earthquakes within this ratio. According to the results, this methodology can extract the abnormal signals in the ULF range of the EM anomalies related to different stages of the EQ preparation, in a ratio that depends of the magnitude.

Acknowledgements. The authors are grateful to CONACyT and Centro de Geociencias of the National University of Mexico (UNAM) for their support and collaboration in this research under the project number 209837. The authors would also like to thank Silvia C. Stroet for editing the English version of this paper. The authors thank to the referees for their observations and recommendations, especially to Natalia A. Smirnova.

Edited by: M. E. Contadakis

Reviewed by: two anonymous referees

\section{References}

$2.3 \mathrm{~h}$ before and 0.8 , and $4.5 \mathrm{~h}$ after the main shock. In summary, this results show that the employed methodology could be adequate to find EM seismic precursors within a range greater than the Dobrovolsky ratio.
Alperovich, L. and Zheludev, V.: Wavelet Transform as a Tool for Detection Precursors of Earthquakes, Phys. Chem. Earth, 23(910), 965-967, 1997. 
Dobrovolsky, I. R., Zubkov, S. I., and Myachkin, V. I.: Estimation of the size of earthquake preparation zones, Pure Appl. Geophys., 117, 1025-1044, 1979.

Fraser-Smith, A. C., Bernardi, A., McGill, P. R., Ladd, M. E., Helliwell, R. A., and Villard, O. G.: Low-frequency magnetic measurements near the epicenter of the Ms 7.1 Loma Prieta earthquake, Geophys. Res. Lett., 17, 1465-1468, 1990.

Gotoh, K., Hayakawa, M., and Smirnova, N.: Fractal analysis of the ULF geomagnetic data obtained at Izu Peninsula, Japan in relation to the nearby earthquake swarm of June-August 2000, Nat. Hazards Earth Syst. Sci., 3, 229-236, doi:10.5194/nhess-3229-2003, 2003.

Grimalsky, V., Kotsarenko, A., Pulinets, S., Koshevaya, S., and Perez-Enriquez, R., On the modulation of intensity of Alfvén resonances before earthquakes: Observations and model, J. Atmos. Sol.-Terr. Phy., 72(1), 1-6, 2010.

Harada, M., Hattori, K., and Isesaki, N.: Transfer function approach to signal discrimination of ULF geomagnetic data, Phys. Chem. Earth, 29, 409-417, 2004.

Hattori, K., Serita, A., Gotoh, K., Yoshino C., Harada, M., Isezaki, N., and Hayakawa M.: ULF geomagnetic anomaly associated with 2000 Izu Islands earthquake swarm, Japan Physics and Chemistry of the Earth, Parts A/B/C, 29(4-9), 425-435, 2004.

Hayakawa, M., Kawate, R., Molchanov, O. A., and Yumoto, K.: Results of ultralow-frequency magnetic field measurements during the Guam earthquake of 8 August 1993, Geophys. Res. Lett., 23, 241-244, 1996.

Hayakawa, M., Ito, T., and Smirnova, N.: Fractal analysis of ULF geomagnetic data associated with the Guam earthquake on August 8, 1993, Geophys. Res. Lett., 26, 2797-2800, 1999.

Hayakawa, M., Hattori, K., and Ohta, K.: Observation of ULF Geomagnetic Variations and Detection of ULF Emissions Associated with Earthquakes: Review (translated from Denki Gakkai Ronbunshi, 126-A(12), December 2006, 1238-1244), Electrical Engineering in Japan, 162(4), 1-8, 2008.

Ida, Y., Yang, D., Li, Q., Sun, H., and Hayakawa, M.: Detection of ULF electromagnetic emissions as a precursor to an earthquake in China with an improved polarization analysis, Nat. Hazards Earth Syst. Sci., 8, 775-777, doi:10.5194/nhess-8-775-2008, 2008.

Ismaguilov, V. S., Kopytenko, Yu. A., Hattori, K., Voronov, P. M., Molchanov, O. A., and Hayakawa, M.: ULF magnetic emissions connected with under sea bottom earthquakes, Nat. Hazards Earth Syst. Sci., 1, 23-31, doi:10.5194/nhess-1-23-2001, 2001.

Johnston, M. J. S.: Review of electric and magnetic fields accompanying seismic and volcanic activity, Surv. Geophys., 18, 441-475, 1997.

Johnston, M. J. S. and Mueller, R. J.: Seismomagnetic observation with the July 8, 1986, ML 5.9 North Palm Springs earthquake, Science, 237, 1201-1203, 1987.

Johnston, M. J. S., Mueller, R. J., and Sasai, Y.: Magnetic field observations in the near-field of the 28 June 1992 M7.3 Landers California, earthquake, B. Seismol. Soc. Am., 84, 792-798, 1994.

Kaiser, G. A.: Friendly Guide to Wavelets, Birkhäuser, Boston, MA, USA, 1994.

Kawate, R., Molchanov, O. A., and Hayakawa, M.: Ultra-Low Frequency magnetic fields during the Guam earthquake of 8 August 1993 and their interpretation, Phys. Earth Planet. In., 105,
229-238, 1998.

Kopytenko, Y. A., Matiashvili, T. G., Voronov, P. M., Kopytenko, E. A., and Molchanov, O. A.: Detection of ultra-low-frecuency emissions and its aftershock activity, based on geomagnetic pulsations data at Dusheti and Vardzia observatories, Phys. Earth Planet. In., 77, 85-95, 1993.

Kopytenko, Y., Ismaguilov, V., Hayakawa, M., Smirnova, N., Troyan, V., and Peterson, Th.: Investigation of the ULF electromagnetic phenomena related to earthquakes: contemporary achievements and the perspectives, Ann. Geofis., 44(2), 325334, 2001.

Kotsarenko, A., Pérez Enrquez, R., López Cruz-Abeyro, J. A., Koshevaya, S., Grimalsky, V., and Zúñiga, F. R.: Analysis of the ULF electromagnetic emission related to seismic activity, Teoloyucan geomagnetic station, 1998-2001, Nat. Hazards Earth Syst. Sci., 4, 679-684, doi:10.5194/nhess-4-679-2004, 2004.

Kotsarenko, A., Molchanov, O., Hayakawa, M., Koshevaya, S., Grimalsky, V., Pérez Enríquez, R., and López CruzAbeyro, J. A.: Investigation of ULF magnetic anomaly during Izu earthquake swarm and Miyakejima volcano eruption at summer 2000, Japan, Nat. Hazards Earth Syst. Sci., 5, 63-69, doi:10.5194/nhess-5-63-2005, 2005.

Kotsarenko, A., Pérez Enríquez, R., López Cruz-Abeyro, J. A., Koshevaya, S., Grimalsky, V., Yutsis, V., and Kremenetsky, I.: ULF geomagnetic anomalies of possible seismogenic origin observed at Teoloyucan station, México, in 1999-2001: Intermediate and Short-Time Analysis, Tectonophysics, 431, 249-262, doi:10.1016/j.tecto.2006.05.036, 2007.

Kushwah, V., Singh, V., and Singh, B.: Ultra low frequency (ULF) amplitude observed at Agra (India) and their association with regional earthquakes, Phys. Chem. Earth, 34, 367-272, 2009.

Mallat, S.: A Wavelet tour of signal processing, 2nd edn., Academic Press, 1999.

Millan-Almaraz, J. R., Romero-Troncoso, R. J., ContrerasMedina, L. M., and Garcia-Perez, A.: Embedded FPGA based induction motor monitoring system with speed drive fed using multiple wavelet analysis, International Symposium on Industrial Embedded Systems, SIES 2008, Montpellier, France, June, 2008, 215-220, 2008.

Molchanov, O. A., Kopytenko, Y. A., Voronov, P. M., Kopytenko, E. A., Matiashvili, T. G., Fraser-Smith, A. C., and Bernardi, A.: Results of ULF Magnetic fieldmeasurements near the epicenters of the Spitak (Ms=6.9) and Loma Prieta (Ms=7.1) earthquakes: comparative anaysis, Geophys. Res. Lett., 19, 1495-1498, 1992.

Parrot, M. and Johnston, M. J. S. (Eds.): Seismoelectromagnetic effects, Phys. Earth Planet. In., 57, 177 pp., 1989.

Serita, A., Hattori, K., Yoshino, C., Hayakawa, M., and Isezaki, N.: Principal component analysis and singular spectrum analysis of ULF geomagnetic data associated with earthquakes, Nat. Hazards Earth Syst. Sci., 5, 685-689, doi:10.5194/nhess-5-6852005, 2005.

Smirnova, N., Hayakawa, M., and Gotoh, K.: Precursory behavior of fractal characteristics of the ULF electromagnetic fields in seismic active zones before strong earthquakes, Phys. Chem. Earth, 29, 445-451, 2004.

Warwick, J. W., Stoker, C., and Meyer, T. R.: Radio emission associated with rock fracture: Possible application to the great Chilean earthquake of May 22, 1960, J. Geophys. Res., 87, 2851-2859, 1982. 